\title{
A APROPRIAÇÃO DAS ÁREAS VERDES PELOS CONDOMÍNIOS RESIDENCIAIS VERTICAIS NO MUNICÍPIO DE SÃO PAULO
}

\author{
Larissa Sayuri Tsuda ${ }^{1}$ \\ (recebido em 13.08.2009 e aceito para publicação em 23.03.2010)

\section{RESUMO}

Esta pesquisa analisa a relação entre a cidade e as áreas verdes urbanas no aspecto específico das áreas verdes criadas pelo mercado imobiliário na cidade de São Paulo. Partiu-se do pressuposto que, nos últimos anos, o verde se tornou um elemento valorizado pelo mercado imobiliário, e se procurou investigar os motivos desse interesse repentino do mercado imobiliário em manter ou criar áreas verdes na cidade. A primeira parte do trabalho trata do processo de implantação das áreas verdes públicas na cidade de São Paulo, e do histórico da valorização das áreas verdes na cidade. A segunda parte do trabalho analisa os empreendimentos residenciais verticais com bosque privativo lançados nos últimos anos na cidade de São Paulo. Foram reunidos dados dos empreendimentos deste tipo lançados na cidade de São Paulo entre 2004 e 2008, por meio de pesquisa dos materiais de divulgação dos empreendimentos. Buscou-se caracterizar o padrão destes empreendimentos, para qual classe estes estão voltados, bem como a localização destes dentro da cidade. Concluiu-se que o condomínio residencial vertical com bosque privativo é um produto voltado à classe de alta renda. $E$ que o acesso às áreas verdes na cidade é, em grande parte, intermediado pelo mercado imobiliário.

Palavras-chave: áreas verdes, mercado imobiliário, bosque privativo.

\section{THE APPROPRIATION OF THE GREEN SPACES BY THE VERTICAL RESIDENTIAL CONDOMINIUMS IN THE CITY OF SÃO PAULO}

\section{ABSTRACT:}

This research analyzes the relation between city and green spaces in the specific aspect of green spaces created by real estate in the city of São Paulo. It starts-off from the assumption that, in recent years, green became a valorized element by the real estate market in the city, and it investigates what the motives are for in this sudden interest of the real estate market in maintaining or creating green spaces in the city of São Paulo. The first part of this research deals with the process of implantation of green public spaces in the city of São Paulo, and about the historic process of valorization of the green spaces in the city. The

\footnotetext{
${ }^{1}$ Geógrafa formada pela FFLCH-USP, São Paulo-SP. E-mail: la_nimrod@hotmail.com
} 
second part focuses on the vertical residential enterprises with private woods released in the market in the last few years in the city of São Paulo. Data of these kind of enterprises were gathered from a date range of 2004 to 2008, based in research of publishing material of these enterprises. It sought to characterize the pattern of these enterprises, for which class they are targeted, as well as the location of them inside the city. It was concluded that vertical residential condominiums with private woods are a product created to the upper income class. And that the access to green spaces in the city is mostly intermediated by real state market.

Keywords: green spaces, real estate market, private woods.

\section{INTRODUÇÃO}

Os parques públicos foram utilizados pelo mercado imobiliário para a especulação da terra ao seu redor desde o século XIX.

Segundo Henrique (2006) o primeiro processo de valorização imobiliária a partir de áreas verdes ocorre no início do século XIX em Londres. Segundo Mumford (1998), a área do atual parque - Regent's Park - pertencia à Igreja Mary-le-Bow e estava prevista para abrigar um cemitério. Mas com o crescimento da cidade e a possibilidade de realização de lucros prevaleceram sobre o uso que se daria à área, a mesma foi loteada. O parque foi criado para aumentar o valor dos terrenos das propriedades vizinhas, ambos financiados por empresas imobiliárias londrinas. "A idéia era que a venda dos lotes e construções nas proximidades do parque pagaria os investimentos gastos no Regent's Park" (Henrique, 2006, p. 68).

Segundo Loureiro (1979), a criação de espaços verdes, mesmo em termos puramente comerciais, uma vez abertos, pagavam-se por si mesmos, por aumentar os valores imobiliários ao longo das propriedades adjacentes. Porém na cidade de São Paulo, ao longo da expansão da sua área construída, houve poucos exemplos de criação de parques públicos pela iniciativa privada. Até a década de 80 , um dos únicos parques construídos pela iniciativa privada - e mantido pela mesma por duas décadas - foi o Parque Siqueira Campos. Este foi construído concomitantemente à Avenida Paulista pelos mesmos empreendedores que lotearam o bairro, com claros fins de especulação imobiliária de seu entorno. Os lotes de frente à avenida eram adquiridos pela elite paulistana da época, enriquecida pelo ciclo do café. O parque, de frente à avenida, era um ponto de encontro desta elite.

Ao longo do século passado, o município de São Paulo sofreu grande expansão urbana, que produziu uma cidade fortemente adensada. Durante esse processo, acredita-se que os agentes imobiliários não deram prioridade à preservação das áreas verdes nem dentro e nem fora dos seus lotes. A escassez de áreas verdes na cidade de São Paulo 
contribuiu para um processo de valorização do espaço de acordo com a sua proximidade a espaços livres públicos, como praças e parques. Assim, as áreas ao redor de vários parques públicos na região do centro expandido são disputadas pelo mercado imobiliário, pois a proximidade a áreas verdes públicas hoje é um grande atrativo na venda de um imóvel. As áreas verdes possuem como principais atrativos proporcionar lazer em meio à natureza, uma vista ampla e agradável, e criar uma distinção de classe social, isto é, proporcionar status ao morador do imóvel.

Os principais parques que são valorizados pelo mercado imobiliário já não possuem uma grande oferta de terrenos disponíveis nas suas proximidades para a implantação de novos empreendimentos, tais como o Parque do Ibirapuera, o Parque da Aclimação e o Parque Villalobos.

Para dar continuidade à valorização do verde, o mercado imobiliário criou uma nova tendência de valorização das áreas verdes: a construção de bosques e parques privativos, como um item de destaque dos empreendimentos residenciais verticais, que funcionam como pequenos espaços verdes privativos.

Visto que a cidade de São Paulo possui um elevado preço da terra, principalmente no seu centro expandido, o fenômeno dos bosques privativos parece ser um contra-senso. $O$ espaço que ocupa um bosque ou parque privativo é amplo, portanto empreendimentos desse tipo necessitam de terrenos grandes, que são deixados livres de construção, para abrigar a área verde. Por outro lado, são construídos prédios cada vez mais altos, para compensar a área deixada livre.

Neste trabalho questiona-se o porquê do mercado imobiliário passar a investir em empreendimentos com grandes áreas verdes. Uma das possíveis respostas para essa indagação é que, ao longo do século passado, o verde se tornou um elemento raro na cidade de São Paulo, e justamente pela sua raridade é agora um elemento caro, ou seja, acessível somente à classe média alta, e apenas nos últimos anos, quando o verde passou a ser visto sob um novo olhar. No mundo contemporâneo o verde significa um momento de paz, relaxamento, desaceleração, anti-stress, sensações muito desejadas diante do frenético ritmo da metrópole.

Este trabalho tem como objetivo principal compreender a relação entre o mercado imobiliário e as áreas verdes através da pesquisa e análise dos empreendimentos residenciais verticais com bosque privativo.

\section{MATERIAIS E MÉTODOS}

\section{Caracterização da área}


A cidade de São Paulo, capital do estado de São Paulo, possui uma população de 10.886.518 habitantes (IBGE, 2007), uma área de $1.523 \mathrm{~km}^{2}$ (IBGE, 2007) e 129,4 km² de áreas verdes (Sempla, 2008).

\section{Procedimentos metodológicos}

Procurou-se encontrar o maior número possível de empreendimentos residenciais verticais com bosque privativo ou parque privativo em construção na cidade de São Paulo atualmente. Desta forma, foi feita uma busca de dados através de materiais de divulgação de empreendimentos residenciais com bosque privativo - tais como websites das incorporadoras, revistas promocionais especializadas e encartes especiais de periódicos sobre mercado imobiliário, reunindo dados que pudessem caracterizar tais empreendimentos. Durante a pesquisa, foram encontrados 20 casos. Através dos dados obtidos, pode-se traçar o padrão geral destes empreendimentos.

Todos os empreendimentos localizados foram organizados na forma de tabela, onde se procurou encontrar e catalogar dados fundamentais, como localização, número de dormitórios, número de andares, número de torres, número de unidades à venda, incorporadora, área do bosque, área do terreno e, quando possível, o valor dos apartamentos, procurando levantar qual é o padrão deste tipo de empreendimento.

A partir dos dados de endereço, utilizou-se o programa de SIG (Sistemas de Informações Geográficas) Maptitude 5.0 para georreferenciar os empreendimentos, a fim de se obter uma idéia da distribuição dos mesmos na cidade. Depois, comparou-se essa distribuição com dados relevantes para o tema: renda média do chefe de domicílio (por distrito) e proximidade a shoppings centers.

\section{RESULTADOS E DISCUSSÃO}

\section{As áreas verdes ao longo do processo de expansão urbana na cidade de São Paulo}

Os parques urbanos da cidade de São Paulo possuem distintos processos de implantação. Os casos mais comuns são a desapropriação de áreas particulares e os Espaços Livres de Arruamento, produtos do parcelamento do solo. Este último é resultado de diversas legislações, que alternadamente regularam o parcelamento do solo. Segundo Bartalini (1996), a primeira lei sobre esse assunto no município de São Paulo foi o Código Arthur Sabóia (Ato 663 de 1934). Este vigorou de 1934 a 1972, e determinava 5\% de espaços livres nos loteamentos situados em zona urbana (1996, p.138). Em 1972, a Lei municipal 7.805 (Lei de Zoneamento) aumenta o índice para 15\%. Posteriormente, a Lei Lehman (Lei Federal 6.766/79), de âmbito federal, foi criada para tentar reverter o quadro de 
deterioração urbano-ambiental nas grandes cidades brasileiras, e passou a regular o parcelamento do solo. A Lei Lehman reservava 35\% dos loteamentos para áreas públicas, como sistema viário, áreas verdes e institucionais. Esta foi substituída pela Lei municipal no $9.413 / 81^{2}$, que regula o parcelamento do solo, e exige ao loteador destinar no mínimo $15 \%$ da área loteada para áreas verdes. Apesar da existência desta legislação, que determina a destinação de parte de um loteamento particular a áreas verdes públicas, a cidade de São Paulo apresenta poucos espaços verdes públicos, voltados para o lazer da população.

Sobre as áreas verdes públicas da cidade de São Paulo, o Plano Diretor Estratégico de São Paulo, Lei no 13.430/02, diz que: "a regra estabelecida pelo 'loteador' é obter o maior número possível de lotes, com supressão total da vegetação existente" (p.63). A partir deste trecho, acredita-se que, durante o processo de expansão urbana, os agentes imobiliários não deram prioridade à preservação das áreas verdes dentro dos seus lotes. Também se afirma que:

Outros fatores ainda podem ser citados como responsáveis por onerar o estoque público de áreas verdes, entre eles, a partir da década de 40, a ocupação de áreas livres por favelas, intensificada nos anos 1970, quando surge mais da metade das atuais 1855 favelas. (2002, p.63)

Em outro trecho do Plano Diretor afirma-se que, do total de favelas cadastradas, "65\% ocupam áreas municipais originalmente destinadas à implantação de áreas verdes" (p.61). Porém, acredita-se que esse dado é vago, e livre para inúmeras interpretações. Pode-se questionar, por exemplo, se estas "áreas destinadas à implantação de áreas verdes” já eram, na época de sua ocupação ilegal, espaços livres públicos, ou se eram vazios urbanos.

Um trabalho desenvolvido pela Sempla (Secretaria Municipal de Planejamento) "Políticas de Terras Urbanas no distrito de São Mateus" (2000) - mostra que nesse distrito grande parte das áreas destinadas ao verde, fruto da lei do parcelamento do solo, é ocupada irregularmente, tanto pela população, que constitui favelas, muitas vezes em áreas de risco, quanto por órgãos públicos, sem prévia análise de prioridades.

No distrito de São Mateus, apenas 7\% dos $1.059 .305 \mathrm{~m}^{2}$ dos Bens de Uso Comum - Área Verde são utilizados como tal, enquanto $31 \%$ permanecem vazios, cerca de $31 \%$ encontram-se invadidas por favelas e habitações em 'auto-construções', $21 \%$ ocupados por equipamentos sociais e $8 \%$ com outros usos (Sempla, 2000, p.17).

\footnotetext{
${ }^{2}$ Dispõe sobre o parcelamento de solo no Município de São Paulo, e dá outras providências. Dispõe que no mínimo $15 \%$ da área de cada projeto de loteamento deve ser reservada às áreas verdes
} 
A partir desses dados percebe-se que nem mesmo a prefeitura respeita a lei de parcelamento do solo, ao ocupar as áreas destinadas ao verde com equipamentos públicos. Segundo a publicação referida, estes problemas decorrem da falta de equipamentos e desorganização das instâncias encarregadas da fiscalização, da inexistência de um cadastro eficiente, da histórica irregularidade de alguns loteamentos e da falta de prioridade que a questão recebe desde sempre (Sempla, 2000, p.7).

A falta de fiscalização por parte da municipalidade, a falta de um mapeamento completo da cidade, e a falta de um cadastro eficiente das áreas verdes públicas são deficiências que contribuíram para que, apesar da existência da lei de parcelamento, muitas áreas verdes públicas fossem omitidas. Battaglia (1995, p.192) menciona as táticas mais utilizadas pelos loteadores para burlar a lei, especialmente com relação à reserva de área verde pública:

- Apresentavam plantas falsas e distintas, uma para a Prefeitura e outra para o Cartório de Registro de Imóveis - que por sua vez aprovava qualquer documento, correspondendo ou não a um projeto aprovado pela prefeitura. Para a Prefeitura, a planta apresentava área verde pública, e para o Cartório a área destinada ao verde era preenchida por lotes.

- Parte de outra propriedade era oferecida como área pública.

- Dois loteamentos aprovados com a mesma área pública.

Além disso, a falta de critérios explícitos na legislação anterior à Lei municipal № 9.413/81, ocasião em que ocorreu a maioria dos loteamentos em São Paulo, permitiu que os loteadores reservassem as piores áreas para os Espaços livres de arruamento, que na maior parte dos casos apresentam topografia acidentada, declividades incompatíveis e riscos de erosão ou inundação (Sempla, 2000, p.7). A falta de oferta de moradia para a população de baixa renda levou a mesma a ocupação destes espaços, onde se originaram favelas e moradias auto-construídas. Esta condição gera o grande problema de população vivendo em áreas de risco, expostos a deslizamentos de terra, inundações e doenças devido a falta de saneamento básico e má utilização dos córregos que passam por estas áreas.

Pode se afirmar que este panorama se apresenta com maior freqüência na periferia da cidade, ou seja, na região menos consolidada da mesma, e onde prevaleceu a expansão urbana baseada no loteamento ilegal, que não respeitava as regras do parcelamento do solo.

O próprio fato de a municipalidade tratar a questão das áreas verdes com pouca prioridade contribuiu para a ocupação das áreas destinadas ao verde por favelas, pois estes espaços destinados ao verde muitas vezes permaneciam vazios e sem uso, ao invés de serem espaços de lazer de uso público. Uma vez vazios, e havendo escassez de moradias voltadas à classe de baixa renda, estas áreas foram sendo ocupadas. 


\section{A valorização do verde na cidade de São Paulo}

Sobre o debate da escassez de parques públicos urbanos, e tomando o exemplo do Parque Siqueira Campos, Kliass (1989, p.242) colocou uma questão: por que esse modelo não se repetiu em outros pontos da cidade? E faz algumas possíveis interpretações sobre o processo: "Teria o nível de exigência do mercado baixado ou o processo de especulação imobiliária conseguiu manter as condições de mercado de tal forma que, diante da escassez, tudo se vendia?"

Apesar do panorama desolador, a mesma autora aponta para possíveis mudanças a partir da década de 90, por razões ambientais críticas:

Talvez o agravamento das qualidades ambientais ao nível que a cidade chegou, possa a empresa privada criar condições juntamente com o poder público de viabilização de parques urbanos que venham a atender, em outro patamar, condizente com a situação atual, as exigências de mercado, extrapolando os benefícios para a população como um todo (1989, p.242).

A partir da década de 90, alguns parques implementados a partir da lei de parcelamento do solo foram alvo de parcerias entre a municipalidade e empresas privadas. Um exemplo é o Parque Burle Marx, no bairro Vila Andrade. Este parque foi inaugurado em 1995 como parte do Projeto Panamby, um bairro criado na mesma época e voltado para a classe de alto poder aquisitivo. A propriedade, uma fazenda às margens do Rio Pinheiros, era um dos últimos grandes terrenos disponíveis numa área que já era valorizada na época. A empresa imobiliária responsável pelo empreendimento doou a área do parque à prefeitura, mediante à lei de parcelamento do solo. Segundo Barroso (2006), o terreno destinado ao parque totaliza $138.279 \mathrm{~m}^{2}$ (28,6 \% da área total loteada). Apesar de ser um parque público municipal, é administrado em parceria com a Fundação Aron Birmann, criada especificamente para este fim.

Outro exemplo é o Parque Colina de São Francisco, com $49.000 \mathrm{~m}^{2}$, inaugurado em 2007. O parque foi construído por uma incorporadora, juntamente com um grande projeto de condomínios residenciais verticais, e recentemente foi doado à municipalidade.

Apesar dos parques terem sido originados de uma lei obrigatória, as incorporadoras assumiram o papel da administração pública ao projetar e construir melhorias nas áreas verdes públicas. As incorporadoras imobiliárias investiram na melhoria do parque, em aspectos de conforto, mobiliário urbano, paisagismo, e investem nos custos de manutenção destes parques, através de parcerias com a municipalidade. Em troca, ambos os parques são muito utilizados pelas incorporadoras como atrativo nas propagandas de venda (folhetos, sites) de condomínios residenciais localizados nas proximidades deles. 
A proximidade a praças e parques é um importante item de valorização de um imóvel, e o mercado imobiliário há muito tempo se aproveita deste aspecto para lançar empreendimentos residenciais de alto padrão próximos aos parques nas áreas mais valorizadas da cidade. Podemos citar, na cidade de São Paulo, alguns parques localizados em áreas valorizadas da cidade: Ibirapuera, Villalobos, Aclimação, Burle Marx e Alfredo Volpi.

Cabe salientar que os parques públicos, por si só, não são elementos valorizadores do espaço, mas dependem de outras características já presentes em um bairro, tais como infra-estrutura, acessibilidade, comércio, serviços, baixos índices de violência, aspectos que se complementam para criar os parques mais "valorizados" da cidade, e os bairros mais valorizados da cidade, no seu entorno. Serpa (2007, p.53) resume, dizendo que: "(...) os parques acrescentam amenidades físicas aos bairros que já possuem melhor infra-estrutura de comércio e serviços, bem como vias expressas para circulação de veículos particulares."

Área verde nas proximidades é apenas uma das amenidades de muitas que atualmente são vendidas junto com um imóvel, que vem normalmente em conjunto e agregam valor ao mesmo. Contudo, as áreas verdes parecem ter se destacado bastante dentre todos os itens de valoração de um imóvel de alto padrão.

\section{Condomínios residenciais verticais com bosque privativo - levantamento de casos na cidade de São Paulo e análise espacial.}

Foram encontrados 20 casos de condomínios residenciais verticais com bosque privativo lançados no período de 2004 a 2008. As principais características destes condomínios foram coletadas e agrupadas nas tabelas 1 e 2 . 
Tabela 1: Características de localização e dimensão do terreno dos condomínios residenciais verticais com bosque privativo lançados no período de 2004 a 2008 na cidade de São Paulo.

\begin{tabular}{|c|c|c|c|c|c|c|c|}
\hline & \begin{tabular}{|l|l|}
$\begin{array}{l}\text { Nome do } \\
\text { empreendimento }\end{array}$ \\
\end{tabular} & Endereço & Bairro divulgado & Distrito & \begin{tabular}{|l|} 
Área do \\
bosque $\left(\mathrm{m}^{2}\right)$ \\
\end{tabular} & Terreno $\left(\mathrm{m}^{2}\right)$ & \begin{tabular}{|l|}
$\begin{array}{l}\text { Incorpo- } \\
\text { radora }\end{array}$ \\
\end{tabular} \\
\hline 1 & Domínio Marajoara & Av. Interlagos, 800 & Jardim Marajoara & Campo Grande & 23000 & 66480 & A \\
\hline 2 & Central Park Mooca & $\begin{array}{l}\text { Av. Cassandoca X R. } \\
\text { Catarina Braida }\end{array}$ & Nova Mooca & Mooca & 15000 & 47400 & $A$ \\
\hline 3 & Central Park Prime & R. José Tabacow, 1 & Tatuapé & Carrão & 11000 & 35246 & A \\
\hline 4 & lepe Golfe & $\begin{array}{l}\text { Av. Eng. Alberto de } \\
\text { Zagottis, } 897\end{array}$ & Golf Club São Paulo & Campo Grande & 8000 & 36400 & $G$ \\
\hline 5 & Ventana - Panamby & $\begin{array}{l}\text { R. Dona Helena Pereira } \\
\text { de Moraes, } 415\end{array}$ & Panamby & Vila Andrade & $\begin{array}{l}\text { Sem } \\
\text { informação }\end{array}$ & 11374 & A \\
\hline 6 & \begin{tabular}{|l} 
Arboris Santana - \\
Naturis
\end{tabular} & Av. Francisco Ranieri & Santana & Mandaqui & 3340 & 8723 & D \\
\hline 7 & Alameda Morumbi & $\begin{array}{l}\text { Av. Giovanni Gronchi, } \\
6829\end{array}$ & Morumbi & Morumbi & 11000 & 34120 & A \\
\hline 8 & Alto do Bosque & $\begin{array}{l}\text { R. Belchior de } \\
\text { Azevedo, } 202\end{array}$ & Alto da Lapa & Vila Leopoldina & $\begin{array}{l}\text { Sem } \\
\text { informação }\end{array}$ & 6840 & C \\
\hline 9 & $\begin{array}{l}\text { Reserva Verde } \\
\text { Perdizes }\end{array}$ & R. Aimbere, 233 & Perdizes & Perdizes & 800 & $\begin{array}{l}\text { Sem } \\
\text { informação }\end{array}$ & C \\
\hline 10 & $\begin{array}{l}\text { Agrias - Villaggio } \\
\text { Panamby* }\end{array}$ & R. Itapaiúna, 1800 & Panamby & Vila Andrade & 58590 & \begin{tabular}{|l} 
Sem \\
informação
\end{tabular} & I \\
\hline 11 & $\begin{array}{l}\text { Coletânea Vila } \\
\text { Mariana }\end{array}$ & R. Conde de Irajá, 142 & Vila Mariana & Vila Mariana & 1700 & 7455 & A \\
\hline 12 & $\begin{array}{l}\text { Helvetia Grand } \\
\text { Quartier - Garten } \\
\text { Haus }\end{array}$ & $\begin{array}{l}\text { R. São Benedito X R. } \\
\text { Marechal Deodoro }\end{array}$ & Alto da Boa Vista & Santo Amaro & 4290 & 9790 & A \\
\hline 13 & Floris Santana & R. Santo Egídio, 655 & Santana & Santana & 1700 & $\begin{array}{l}\text { Sem } \\
\text { informação }\end{array}$ & A \\
\hline 14 & $\begin{array}{l}\text { Helvetia Grand } \\
\text { Quartier - Alpenhaus }\end{array}$ & $\begin{array}{l}\text { R. São Benedito X R. } \\
\text { Marechal Deodoro }\end{array}$ & Alto da Boa Vista & Santo Amaro & 1600 & 4950 & A \\
\hline 15 & $\begin{array}{l}\text { Residencial Reserva } \\
\text { dos Lagos }\end{array}$ & Av. Miguel Yunes, 777 & Interlagos & Campo Grande & \begin{tabular}{|l|}
$\begin{array}{l}\text { Sem } \\
\text { informação }\end{array}$ \\
\end{tabular} & 28000 & E \\
\hline 16 & $\begin{array}{l}\text { Paineiras - } \\
\text { Condomínio Reserva } \\
\text { Casa Grande* } \\
\end{array}$ & $\begin{array}{l}\text { Av. Washington Luiz, } \\
1628\end{array}$ & Chácara Flora & Campo Grande & 54000 & 74000 & $F$ \\
\hline 17 & Clima Do Bosque & $\begin{array}{l}\text { Av. Alberto Ramos, } \\
130\end{array}$ & Vila Prudente & São Lucas & \begin{tabular}{|l} 
Sem \\
informação
\end{tabular} & 7982 & B \\
\hline 18 & $\begin{array}{l}\text { Paulistania Bosque } \\
\text { Residencial }\end{array}$ & R. Pensilvânia, 114 & Brooklin & Itaim Bibi & 7600 & \begin{tabular}{|l|} 
Sem \\
informação
\end{tabular} & A \\
\hline 19 & Viverde & \begin{tabular}{|l} 
Av. Ministro Petrônio \\
Portela, 2001
\end{tabular} & Freguesia Do Ó & Freguesia Do Ó & 11995 & 20000 & $\mathrm{H}$ \\
\hline 20 & Splendor Square & R.Santa Elvira, 149 & Tatuapé & Tatuapé & 853 & 5824 & B \\
\hline
\end{tabular}

*Apesar destes empreendimentos não serem novos, possuem torres em fase de lançamento.

Através dos dados obtidos na tabela 1 pode-se observar as seguintes características dos empreendimentos com bosque privativo: (1) Possuem terrenos grandes; (2) Apresentam 
variação no tamanho dos bosques - desde $800 \mathrm{~m}^{2}$, no empreendimento Reserva Verde Perdizes, a $58.590 \mathrm{~m}^{2}$, no empreendimento Villagio Panamby; (3) $50 \%$ dos lançamentos lançados por apenas uma incorporadora. Já duas incorporadoras, B e C possuem, cada uma, dois empreendimentos com bosque privativo. Todas as outras possuem apenas um empreendimento cada; (4) O único bosque que tem acesso ao público, apesar de ser privado, é o do empreendimento Paulistania Bosque Residencial.

Tabela 2: Características das unidades habitacionais dos condomínios residenciais verticais com bosque privativo lançados no período de 2004 a 2008 na cidade de São Paulo.

\begin{tabular}{|c|c|c|c|c|c|c|c|}
\hline & $\begin{array}{c}\text { Nome do } \\
\text { empreendimento }\end{array}$ & $\begin{array}{c}\begin{array}{c}\text { Área do Apto } \\
\left(\mathrm{em} \mathrm{m}^{2}\right)\end{array} \\
\end{array}$ & $\begin{array}{c}\text { № } \\
\text { Unidades } \\
\end{array}$ & \begin{tabular}{|c|} 
№ \\
Dormitórios \\
\end{tabular} & Andares & Torres & Preço (R\$) \\
\hline 1 & Domínio Marajoara & 160 a 232 & 594 & 3 e 4 & 27 & 7 & Sem informação \\
\hline 2 & Central Park Mooca & 115 a 200 & 564 & 3 e 4 & 25 & 9 & $\begin{array}{c}\text { De } 303.997 \text { a } \\
642.992 \\
\end{array}$ \\
\hline 3 & Central Park Prime & 176 a 315 & 532 & 3 & 25 & 8 & Sem informação \\
\hline 4 & lepê Golfe & 149 a 233 & 336 & 4 & 27 & 6 & $\begin{array}{c}519.700(185,5 \\
\left.m^{2}\right)\end{array}$ \\
\hline 5 & Ventana - Panamby & 113 a 176 & 232 & 3 e 4 & 24 & 3 & $\begin{array}{c}\text { De } 346.610 \mathrm{a} \\
587.000\end{array}$ \\
\hline 6 & $\begin{array}{c}\text { Arboris Santana - } \\
\text { Naturis }\end{array}$ & 104 & 104 & 3 & 13 & 2 & $\begin{array}{c}\text { A partir de } \\
393.000\end{array}$ \\
\hline 7 & Alameda Morumbi & 95 e 124 & 448 & 3 e 4 & 28 & 2 & 273.000 \\
\hline 8 & Alto do Bosque & 167 a 185 & 46 & 4 & 23 & 2 & Sem informação \\
\hline 9 & $\begin{array}{c}\text { Reserva Verde } \\
\text { Perdizes }\end{array}$ & 196 a 251 & $\begin{array}{c}\text { Sem } \\
\text { informação }\end{array}$ & 4 & 27 & 2 & Sem informação \\
\hline 10 & $\begin{array}{c}\text { Agrias - Villaggio } \\
\text { Panamby }^{\star}\end{array}$ & 207 & 100 & 4 & 25 & 1 & $\begin{array}{c}673.000 \mathrm{a} \\
937.000 \\
\end{array}$ \\
\hline 11 & $\begin{array}{l}\text { Coletânea Vila } \\
\text { Mariana }\end{array}$ & 208 e 213 & 96 & 4 & 25 & 2 & 850.000 \\
\hline 12 & $\begin{array}{c}\text { Helvetia Grand } \\
\text { Quartier - Garten Haus }\end{array}$ & 126 e 146 & 64 & 4 & 8 & 3 & $\begin{array}{c}\text { De } 413.000 \mathrm{a} \\
\quad 492.000\end{array}$ \\
\hline 13 & Floris Santana & 120 a 150 & $\begin{array}{c}\text { Sem } \\
\text { informação }\end{array}$ & 4 & 29 & 1 & Sem informação \\
\hline 14 & $\begin{array}{c}\text { Helvetia Grand } \\
\text { Quartier - Alpenhaus }\end{array}$ & 139 e 145 & 40 & 3 e 4 & 5 & 2 & $\begin{array}{c}\text { De } 520.000 \text { a } \\
688.000 \\
\end{array}$ \\
\hline 15 & $\begin{array}{l}\text { Residencial Reserva } \\
\text { dos Lagos }\end{array}$ & 61 a 72 & 302 & 2 e 3 & 17 & 3 & $\begin{array}{c}\text { A partir de } \\
155.340 \\
\end{array}$ \\
\hline 16 & $\begin{array}{c}\text { Edifício Paineiras - } \\
\text { Condomínio Reserva } \\
\text { Casa Grande* }^{*}\end{array}$ & 370 & 140 & 4 & Sem Inf. & 6 & Sem informação \\
\hline 17 & Clima do Bosque & 96 e 127 & 208 & 3 e 4 & 26 & 2 & Sem informação \\
\hline 18 & $\begin{array}{c}\text { Paulistania Bosque } \\
\text { Residencial }\end{array}$ & 178 e 229 & 350 & 4 & 36 & 2 & 650.000 \\
\hline 19 & Viverde & 78 & 500 & 3 & 25 & 5 & 196.540 \\
\hline 20 & Splendor Square & 167 a 208 & 112 & 4 & 28 & 2 & Sem informação \\
\hline
\end{tabular}

* Apesar destes empreendimentos não serem novos, possuem torres em fase de lançamento.

Através dos dados obtidos na tabela 2 pode-se traçar o padrão geral das unidades habitacionais destes empreendimentos: (a) apartamentos de 3 ou 4 dormitórios; (b) mais de 
20 andares por torre; (c) grande número de unidades; (d) mais de uma torre por empreendimento;

A partir dos dados obtidos nas tabelas, se notou que para compensar a área livre de construção, reservada às áreas de bosque privativo, os empreendimentos estudados possuem um grande número de unidades residenciais, obtidos através de prédios altos e mais de um edifício por condomínio. 


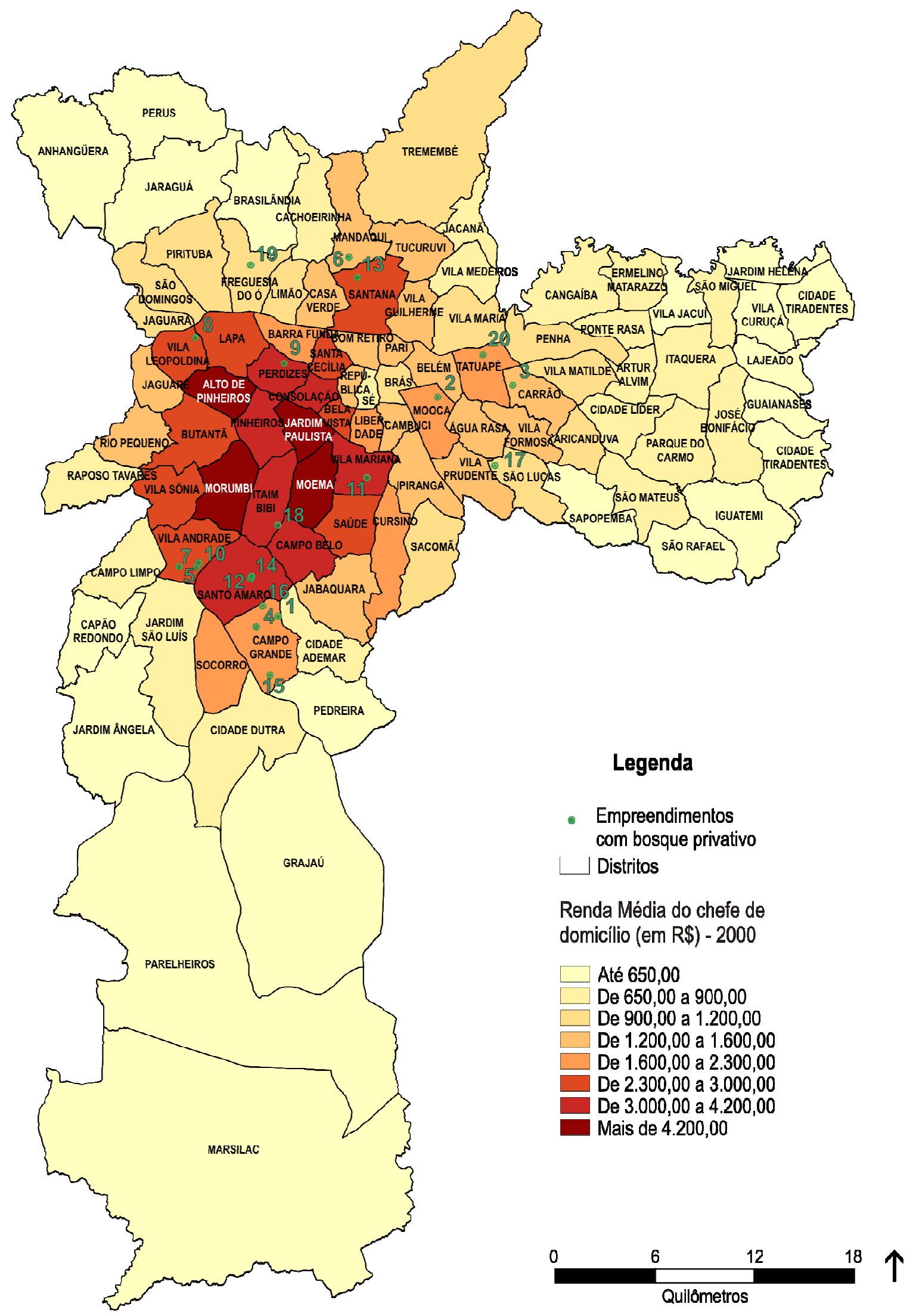

Fonte: SMT/Atlas do Trabalho e Desenvolvimento e IBGE

Elaboração: Larissa Tsuda 
Figura 1: Mapa da localização dos empreendimentos residenciais verticais com bosque privativo e renda média do chefe de domicílio por distrito

Ao observar na Figura 1 a localização dos condomínios com bosque privativo e a renda média do chefe de domicílio por distrito percebe-se que a maioria (80\%) dos condomínios está inserida nos distritos que possuem renda média por chefe de domicílio acima de $R \$ 1.600,00$ (IBGE, 2000). Os condomínios que se localizam nos distritos com renda média inferior a $\mathrm{R} \$ 1.600,00$ estão: ou na Zona Leste, nos distritos Carrão e São Lucas - próximos à Mooca e Tatuapé, que estão sendo alvo das incorporadoras imobiliárias e estão sofrendo um rápido processo de valorização -, ou na Zona Norte, no distrito do Mandaqui, vizinho à Santana, distrito mais rico da Zona Norte. Deve ser ressaltado que o condomínio localizado no Mandaqui é vizinho ao recém-inaugurado Santana Parque Shopping, exemplificando a forte relação dos empreendimentos com área verde privativa e a proximidade destes a ampla gama de comércio e serviços. Outro empreendimento está localizado no distrito da Freguesia do Ó, Zona Norte da cidade, cuja renda média por domicílio é $\mathrm{R} \$ 1.111,49$. Nenhum empreendimento está localizado em distritos paulistanos que possuem renda média por chefe de domicílio inferior à $\mathrm{R} \$ 900,00$. Portanto, há uma forte correlação entre distritos de maior renda por chefe de domicílio e os empreendimentos estudados. 
TSUDA, L. S.

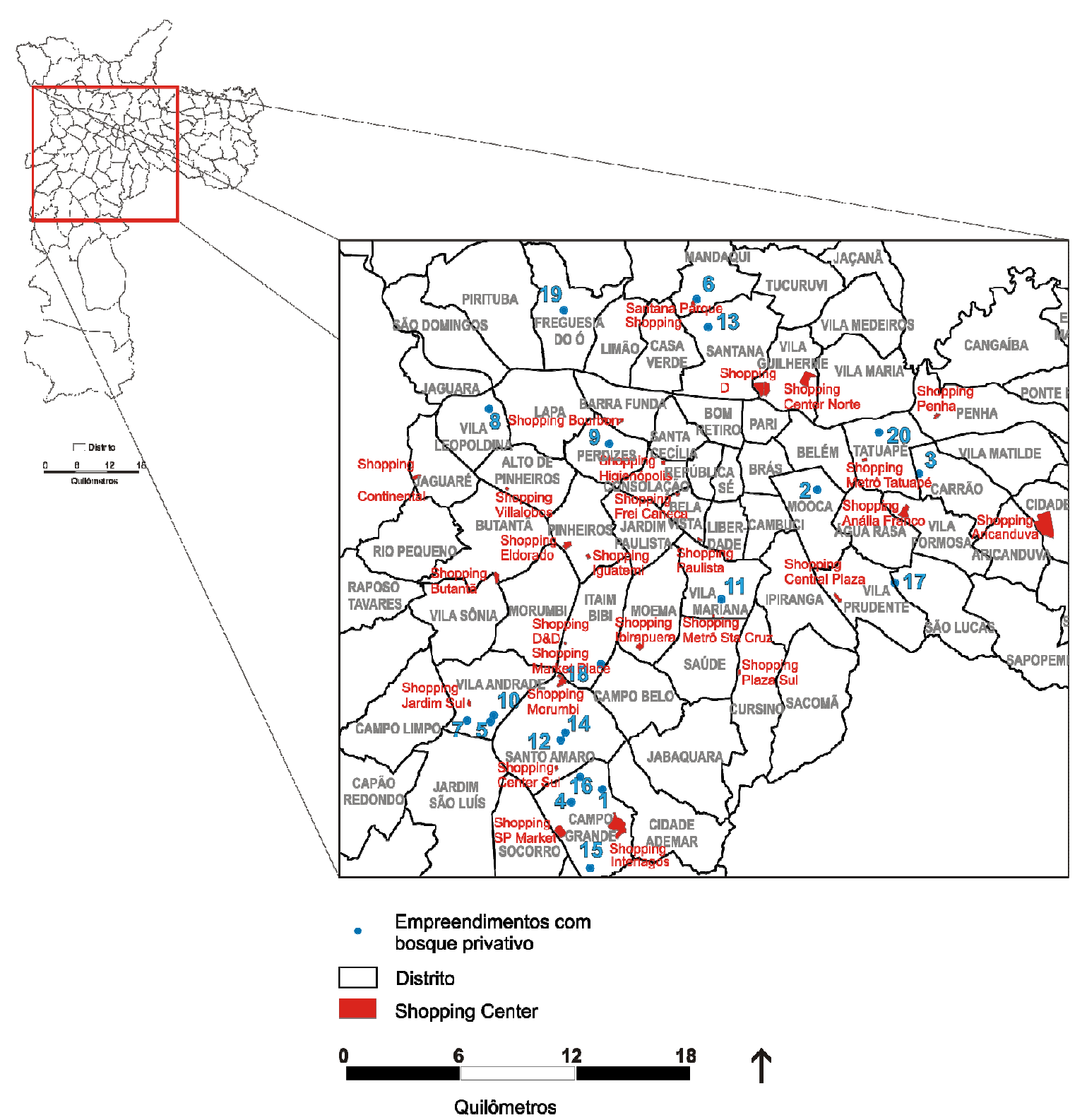

Fonte: Secretaria Municipal de Desenvolvimento Urbano/PMSP Elaboraçãa: Larissa Tsuda

Figura 2: Mapa da localização dos empreendimentos residenciais verticais com bosque privativo e localização dos Shoppings Centers

A Figura 2 mostra que há uma clara correlação entre a localização de empreendimentos residenciais com bosque privativo e a localização dos shoppings centers na cidade de São Paulo, reforçando a afirmação de que áreas verdes são amenidades urbanas que valorizam os empreendimentos imobiliários, desde que os bairros onde estão inseridos já possuam boa infra-estrutura e proximidade a comércio e serviços. Nas propagandas de lançamentos imobiliários pesquisados, ao falar da localização, muitos chamam a atenção para o verde, mas também para a proximidade a shoppings centers. 


\section{Sobre a descrição e a localização dos bosques privativos dentro dos condomínios}

As propagandas dos lançamentos residenciais verticais com área verde encontradas nos sites das incorporadoras descrevem muito pouco como serão essas áreas verdes, apesar destas receberem forte destaque, na forma de imagem e slogan. Um dos únicos com uma boa descrição das áreas verdes é o Paulistania Bosque Residencial. Ele também se destaca entre os outros, pois se trata de uma área de preservação ambiental, e por ser um bosque privado de uso público. Outros empreendimentos possuem "imagens meramente ilustrativas" dos bosques, porém não necessariamente representam o bosque na realidade. No site do empreendimento Central Park Prime, inclusive, há uma observação dizendo que as imagens apresentam perspectiva artística com vegetação de porte adulto, que será atingida após anos da entrega do empreendimento, ou seja, que o porte da vegetação demorará anos para atingir o porte correspondente à imagem, já que nesse caso as árvores serão todas plantadas pela construtora.

Ao observar as ilustrações da Figura 3, das implantações (plantas dos projetos) dos condomínios com bosque privativo, percebe-se que em quatro casos - Central Park Mooca, Central Park Prime, Domínio Marajoara e Reserva Casa Grande - o bosque, ou parque, está no centro do terreno, e cercado por torres de prédios. Em outros quatro casos - Coletânea Vila Mariana, Alameda Morumbi, Floris Santana e Arboris Santana-Naturis -, o bosque aparece do lado oposto à rua, ou seja, no fundo do terreno. Nestes dois tipos de configuração, o bosque aparentemente não será visível a partir da rua, ficando reservado, quase escondido, como um refúgio para os moradores do condomínio. Em quatro casos Paulistania Bosque Residencial, Reserva Verde Perdizes, lepê Golf, Alto do Bosque - o bosque fica de frente à rua. Porém, não se sabe se estes serão cercados por muros altos, ou se serão visíveis a partir da rua.

Não foi encontrado material representativo da implantação dos empreendimentos Splendor Square, Clima do Bosque, Villagio Panamby e Residencial Reserva dos Lagos no website das incorporadoras responsáveis por estes empreendimentos. 
Implantação dos empreendimentos residenciais verticais com bosque privativo:
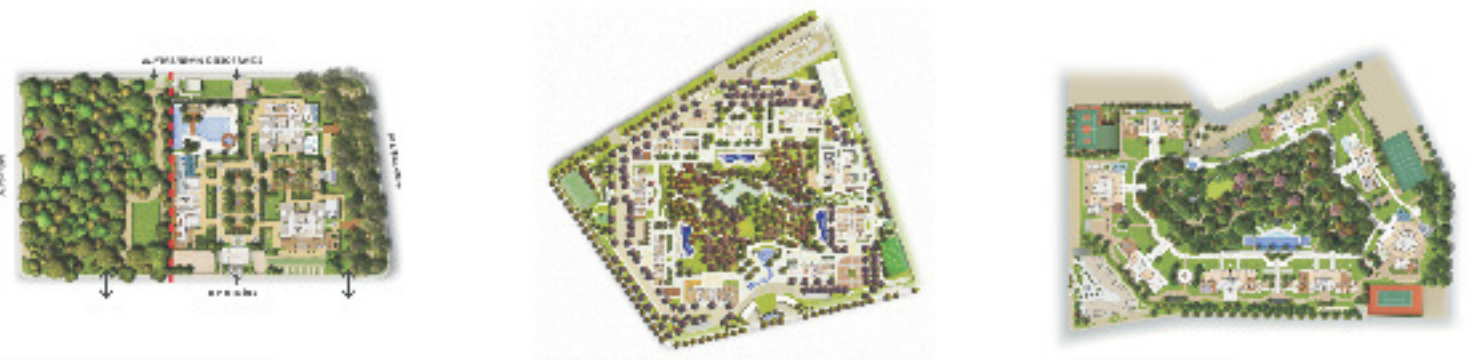

Pathotria Boague Reaidencia

Cental Park Mooca

Certra Park Pime
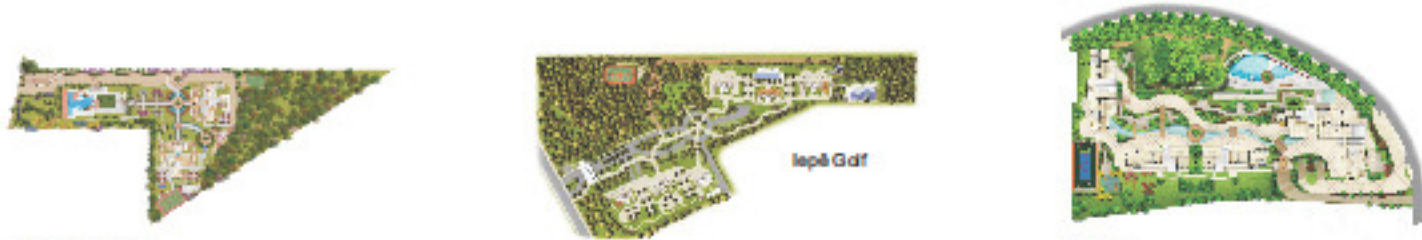

Nameda Monnti

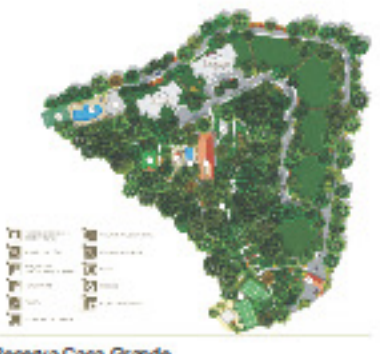

vartane

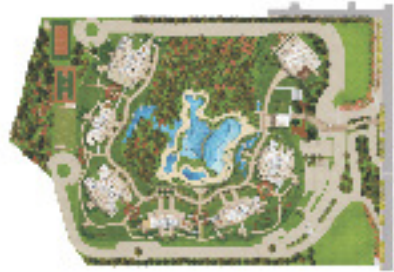

Domitio Marapara

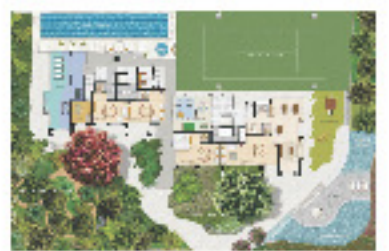

Recerva Verde Fendina
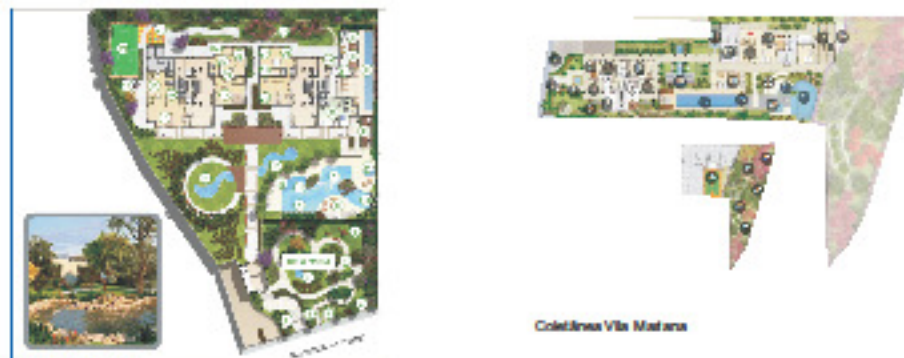

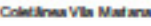

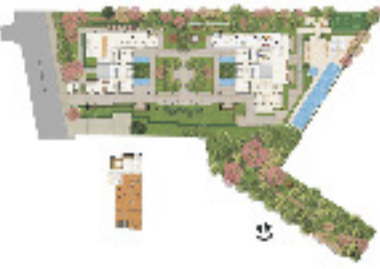

Nahria Adoris Santona
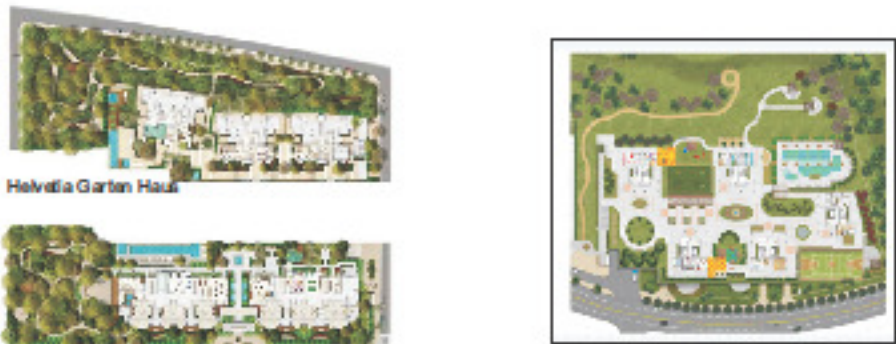

Viverde

Forls Sertane

Hevesa CondQuarter

Figura 3: Implantação dos empreendimentos residenciais verticais com bosque privativo 


\section{CONCLUSÃO}

Através da pesquisa, pode-se confirmar um novo e crescente interesse por áreas verdes que não é imposto pela legislação urbanística. A valorização das áreas verdes não é apenas uma imposição do mercado imobiliário, mas faz parte de um contexto maior, uma nova racionalidade, promovida também pela população, que deseja morar perto do verde. Este pensamento é captado pelas empresas do setor imobiliário, que adquirem uma nova visão do verde, como um produto a ser vendido e que agrega valor ao empreendimento quando aliado a outros aspectos como a localização e a presença de ampla gama de serviços próximos - tornando-o acessível somente às classes de alta renda.

Em grande parte, a valorização do verde na cidade de São Paulo pode ser explicada pela sua própria escassez, já que todo "produto" que se torna escasso sofre um processo de valorização.

O acesso às áreas verdes na cidade, portanto, é intermediado pelos incorporadores que atuam no mercado imobiliário. $O$ fato de o verde ser um atrativo na compra de uma residência leva o mercado a criar formas de melhorar o verde, através de parcerias, restaurando áreas verdes públicas, mantendo áreas que já possuem verde significativo e até criando áreas verdes a partir de terrenos completamente áridos. Porém, o mercado estabelece o uso privativo em parte destas áreas verdes criadas. $\mathrm{O}$ uso privativo de áreas verdes é um dos fatores que promovem a fragmentação do espaço urbano.

\section{REFERÊNCIAS BIBLIOGRÁFICAS}

BARROSO, Daniella Almeida. Projeto urbanístico Panamby : uma "nova cidade" dentro de São Paulo, 2006. 79 p._Tese (Metrado em Geografia). Faculdade de Filosofia, Letras e Ciências Humanas, Universidade de São Paulo, São Paulo.

BARTALINI, Vladimir. Os parques públicos municipais de São Paulo. Revista Paisagem e Ambiente. São Paulo, n. 9, p.125-148, 1996.

BATTAGLIA, Luisa. Cadastros e registros fundiários. A institucionalização do descontrole sobre o espaço no Brasil, 1995. 329 p. Tese (Doutorado em Arquitetura e Urbanismo). Faculdade de Arquitetura e Urbanismo, Universidade de São Paulo, São Paulo.

HENRIQUE, Wendel. A cidade e a natureza: a apropriação, a valorização e a sofisticação da natureza nos empreendimentos imobiliários de alto padrão em São Paulo. Revista GEOUSP - Espaço e Tempo, São Paulo, № 20, pp. 65 - 77, 2006.

KLIASS, Rosa Grena. A evolução dos parques urbanos na cidade de São Paulo, 1989. Tese (Mestrado em Arquitetura e Urbanismo). Faculdade de Arquitetura e Urbanismo, Universidade de São Paulo, São Paulo.

IBGE - Instituto Brasileiro de Geografia e Estatística. Disponível em: http://www.ibge.gov.br/cidadesat, acessado em 15/11/2009. 
LOUREIRO, Maria Amélia Salgado. A cidade e as áreas verdes. São Paulo, Secretaria de Serviços e Obras da Prefeitura do Município, 1979.

MUMFORD, Lewis. A cidade na história. Suas origens, transformações e perspectivas. São Paulo: Martins Fontes, 1998.

Revista ÉPOCA. № 448 Guia Imobiliário (encarte especial). p 54-56, 24/09/07.

SANTOS, Milton. A natureza do espaço. Técnica e tempo, razão e emoção. São Paulo: Editora Hucitec, 1996.

SEMPLA - Secretaria Municipal de Planejamento no Município de São Paulo. Política de destinação das terras públicas municipais - Um plano para São Mateus, São Paulo, 2000. 2012). São Paulo: SENAC, 2004.

Plano Diretor Estratégico do Município de São Paulo (2002.Infocidade - Índice de Áreas Verdes, disponível em: http://sempla.prefeitura.sp.gov.br/infocidade/htmls/2 Indice de Areas verdes 2008 514.ht $\underline{\mathrm{ml}}$, acessado em 15/10/2009.

SERPA, Angelo. $O$ espaço público na cidade contemporânea. São Paulo: Contexto, 2007. SMTrab - Secretaria Municipal do Trabalho. Atlas do Trabalho e Desenvolvimento da Cidade de São Paulo - Atlas Municipal, 2007

SVMA - Secretaria do Verde e Meio Ambiente do Município de São Paulo. Atlas Ambiental do Município de São Paulo, 2006 